KOPSTEIN, Marcos Antunes; SILVA, Bruna Lopes. A flexibilização do direito trabalhista brasileiro. Revista Eletrônica Direito e Política, Programa de Pós-Graduação Stricto Sensu em Ciência Jurídica da UNIVALI, Itajaí, v.14, n.2, $2^{\circ}$ quadrimestre de 2019. Disponível em: www.univali.br/direitoepolitica - ISSN 1980-7791

\title{
A FLEXIBILIZAÇÃO DO DIREITO TRABALHISTA BRASILEIRO
}

\author{
THE FLEXIBILIZATION OF BRAZILIAN'S LABOR LAW
}

\section{Marcos Antunes Kopstein ${ }^{1}$ \\ Bruna Lopes Silva ${ }^{2}$}

\begin{abstract}
RESUMO
O direito do trabalho brasileiro caracteriza-se pelo caráter preservacionista, mas vê-se uma crescente flexibilização do trabalho, seja através de negociações coletivas ou de desregulamentação de normas trabalhistas. Os princípios basilares do direito laboral, principalmente o elementar princípio da proteção, regem todas as formas da relação de trabalho, mas evidencia-se uma transformação do direito do trabalho, convertendo sua lógica preservacionista para uma lógica de flexibilidade. Então, afirma-se que a flexibilização decorre das mudanças de panorama econômico, resultante de crises e advento de novas tecnologias. Nesse interim, antevê-se modificações na legislação trabalhista pátria, maiormente da Consolidação das Leis Trabalhistas, as quais demonstram claramente a flexibilização do direito laboral no Brasil.
\end{abstract}

PALAVRAS-CHAVE: Desregulamentação; Direito do Trabalho; flexibilização do trabalho; negociação coletiva.

\section{ABSTRACT}

The Brazilian's labor law is characterized by preservationist character, but is noted an increasing of work's flexibility, either through collective bargaining or deregulation of labor standards. The basic principles of the labor law, especially the basic principle of protection, governing all forms of the employment relationship, but there is evidence of a transformation of labor law by converting its preservationist logic for a flexible logic. So, it is stated that flexibility stems from changes in economic outlook resulting crisis and the advent of new technologies. In the meantime, changes in labor law are expected in the country, mainly in the Consolidation of Labor Law, which clearly demonstrate the flexibilization of labor law in Brazil.

\footnotetext{
${ }_{1}^{1}$ Mestrando em Ensino de Humanidades e Linguagens pela Universidade Franciscana- UFN. Bolsista PROSUC/CAPES. Especialista em Direito do Trabalho pela UFN. Bacharel em Direito pela Faculdade de Direito de Santa Maria- FADISMA. Advogado. Santa Maria, Rio Grande do Sul, Brasil. E-mail: marcoskopstein@hotmail.com.

2 Bacharela em Relações Internacionais pela Universidade Federal de Santa Maria - UFSM. Graduanda em Direito pela Universidade Franciscana-UFN. Santa Maria, Rio Grande do Sul, Brasil. E-mail: bruna.Iopesilva@hotmail.com.
} 
KOPSTEIN, Marcos Antunes; SILVA, Bruna Lopes. A flexibilização do direito trabalhista brasileiro. Revista Eletrônica Direito e Política, Programa de Pós-Graduação Stricto Sensu em Ciência Jurídica da UNIVALI, Itajaí, v.14, n.2, 20 quadrimestre de 2019. Disponível em: www.univali.br/direitoepolitica - ISSN 1980-7791

KEYWORDS: Collective bargaining; deregulation; flexible working; Labor Law.

\section{INTRODUÇÃO}

O direito do trabalho, no Brasil, tem passado por transformações no que se tange ao seu caráter preservacionista em prol da parte considerada mais frágil da relação laboral, o empregado. Tais transformações decorrem de uma quebra quanto à lógica da preservação ao trabalhador, moldando-se uma condição mais complacente do Poder Judiciário e do Poder Legislativo quanto à relação laboral, seja através de desregulamentação de normas trabalhistas ou da própria flexibilização de interpretação de tais regramentos.

Atualmente, torna-se perceptível uma alteração de entendimento quanto aos princípios basilares do direito trabalhista, sobretudo, ao princípio da proteção do trabalhador, pois se evidencia uma mudança de perspectivas quanto aos regramentos, outrora, rígidos e, recentemente, pautados pelo incentivo cada vez maior à negociação coletiva, além da clara desregulamentação de normas laborais pelo Poder Legislativo, maiormente através da Lei $13.367 / 17$, que trouxe mudanças significativas à Consolidação das Leis Trabalhistas (CLT).

A justificativa principal para tantas mudanças adentra, principalmente, sob a lógica política e empresarial, no aspecto de que a sociedade, altamente marcada pela competividade capitalista e pela incessante busca pelo crescimento econômico, necessitava urgentemente de novas adequações laborais para, assim, aquecer o mercado de trabalho e evitar ou combater o desemprego em massa, ou seja, o principal motivo para tamanhas mudanças na estrutura laboral brasileira adentra no aspecto da modernização das relações de trabalho.

Ainda, em um Brasil assolado pela crise econômica e que urge por mudanças drásticas que possam mudar seu panorama político-econômico, readequando-o economicamente ao cenário internacional, a flexibilização do trabalho mostra-se um tema marcado pela inevitabilidade da modificação tanto legal quanto doutrinária do direito trabalhista brasileiro. 
KOPSTEIN, Marcos Antunes; SILVA, Bruna Lopes. A flexibilização do direito trabalhista brasileiro. Revista Eletrônica Direito e Política, Programa de Pós-Graduação Stricto Sensu em Ciência Jurídica da UNIVALI, Itajaí, v.14, n.2, $2^{\circ}$ quadrimestre de 2019. Disponível em: www.univali.br/direitoepolitica - ISSN 1980-7791

O processo de flexibilização do trabalho tornou-se evidente a todos os trabalhadores com o advento da já referida Lei 13.367/17 que alterou, revogou e acrescentou artigos na CLT, flexibilizando aspectos referentes à jornada de trabalho, citando, principalmente, a utilização de banco de horas em prol do percebimento de pagamento por horas extraordinárias, da ampliação da possibilidade da terceirização para atividades fins das empresas tomadoras de serviços, além do fomento por acordos ou convenções coletivas entre empresas, sindicatos e trabalhadores, dentre outras modificações que tornaram menos rígidas as legislações trabalhistas no país.

Ademais, importante ressaltar que a temática abordada é propícia a intensas divergências entre juristas e doutrinadores relativas aos questionamentos que surgem das novas mudanças no mercado de trabalho brasileiro: será estimulada a criação de novos empregos ou será tornada ainda mais débil a posição do empregado, parte mais frágil da relação laboral?

Nesse ínterim, importante salientar que o método empregado para realizar o presente artigo é o dedutivo, na medida em que parte de uma premissa maior, qual seja, a possibilidade de flexibilização do direito do trabalho brasileiro através da desregulamentação de normas trabalhistas e incentivo à negociação coletiva.

Salienta-se que a pesquisa pautou-se, primordialmente, por auxílio bibliográfico, pois as premissas foram elencadas a partir de livros, artigos e doutrinas. Além disso, teve-se como vital, a análise documental dos princípios e regramentos trabalhistas, por intermédio da Constituição Federal de 1988 e da CLT.

Por conseguinte, será pontuada, de maneira mais minuciosa, no presente artigo, a atual importância do tema para o trabalhador e para a sociedade brasileira, latente com o recente processo de flexibilização do trabalho, uma vez que o reflexo da sociedade capitalista mais competitiva aliada ao advento de novas tecnologias, que permitem novas formas de labor e de controle de jornada, gera mudanças drásticas no mercado de trabalho brasileiro.

Logo, este artigo abarcará questões relativas ao protecionismo estabelecido pelo direito trabalhista que, além de contar com análise principiológica, examinará a 
KOPSTEIN, Marcos Antunes; SILVA, Bruna Lopes. A flexibilização do direito trabalhista brasileiro. Revista Eletrônica Direito e Política, Programa de Pós-Graduação Stricto Sensu em Ciência Jurídica da UNIVALI, Itajaí, v.14, n.2, $2^{\circ}$ quadrimestre de 2019. Disponível em: www.univali.br/direitoepolitica - ISSN 1980-7791

quebra desse paradigma, por meio da descaracterização da lógica da preservação para uma lógica de flexibilidade.

\section{O DIREITO TRABALHISTA NO BRASIL}

\subsection{Do caráter protecionista}

Uma das características mais notórias do direito do trabalho brasileiro é o seu caráter protecionista, que encontra previsão tanto na Constituição Federal de 1988 (CF/88), quanto na CLT e em leis trabalhistas esparsas. Tal caráter visa resguardar a parte considerada hipossuficiente da relação laboral, qual seja, o empregado.

Para tanto, importante expor que uma grande gama de garantias aos trabalhadores encontra disposição no basilar artigo 70 da Lei Maior, que salvaguarda e assegura o cumprimento dessas garantias aos trabalhadores. Nesse sentido, diferentemente das Constituições Federais anteriores às de 1988, as garantias constitucionais aos trabalhadores encontram amparo na subseção "Dos Direitos e Garantias Fundamentais", no Capítulo II, Título II, da CF/88. A 
KOPSTEIN, Marcos Antunes; SILVA, Bruna Lopes. A flexibilização do direito trabalhista brasileiro. Revista Eletrônica Direito e Política, Programa de Pós-Graduação Stricto Sensu em Ciência Jurídica da UNIVALI, Itajaí, v.14, n.2, 20 quadrimestre de 2019. Disponível em: www.univali.br/direitoepolitica - ISSN 1980-7791

\section{adequação das disposições protecionistas criou, no seu artigo 703, segundo Sérgio}

Pinto Martins 4 "uma verdadeira CLT", ao elencar tantos preceitos.

${ }^{3}$ Art. 70 São direitos dos trabalhadores urbanos e rurais, além de outros que visem à melhoria de sua condição social:I - relação de emprego protegida contra despedida arbitrária ou sem justa causa, nos termos de lei complementar, que preverá indenização compensatória, dentre outros direitos; II - seguro-desemprego, em caso de desemprego involuntário; III - fundo de garantia do tempo de serviço; IV - salário mínimo , fixado em lei, nacionalmente unificado, capaz de atender a suas necessidades vitais básicas e às de sua família com moradia, alimentação, educação, saúde, lazer, vestuário, higiene, transporte e previdência social, com reajustes periódicos que Ihe preservem o poder aquisitivo, sendo vedada sua vinculação para qualquer fim; $V$ - piso salarial proporcional à extensão e à complexidade do trabalho; VI - irredutibilidade do salário, salvo o disposto em convenção ou acordo coletivo; VII - garantia de salário, nunca inferior ao mínimo, para os que percebem remuneração variável; VIII - décimo terceiro salário com base na remuneração integral ou no valor da aposentadoria; IX - remuneração do trabalho noturno superior à do diurno; X - proteção do salário na forma da lei, constituindo crime sua retenção dolosa; XI participação nos lucros, ou resultados, desvinculada da remuneração, e, excepcionalmente, participação na gestão da empresa, conforme definido em lei; XII - salário-família pago em razão do dependente do trabalhador de baixa renda nos termos da lei; XIII - duração do trabalho normal não superior a oito horas diárias e quarenta e quatro semanais, facultada a compensação de horários e a redução da jornada, mediante acordo ou convenção coletiva de trabalho; XIV - jornada de seis horas para o trabalho realizado em turnos ininterruptos de revezamento, salvo negociação coletiva; XV - repouso semanal remunerado, preferencialmente aos domingos; XVI - remuneração do serviço extraordinário superior, no mínimo, em cinquenta por cento à do normal; XVII - gozo de férias anuais remuneradas com, pelo menos, um terço a mais do que o salário normal; XVIII licença à gestante, sem prejuízo do emprego e do salário, com a duração de cento e vinte dias; XIX - licença-paternidade, nos termos fixados em lei; XX - proteção do mercado de trabalho da mulher, mediante incentivos específicos, nos termos da lei; XXI - aviso prévio proporcional ao tempo de serviço, sendo no mínimo de trinta dias, nos termos da lei; XXII - redução dos riscos inerentes ao trabalho, por meio de normas de saúde, higiene e segurança; XXIII - adicional de remuneração para as atividades penosas, insalubres ou perigosas, na forma da lei; XXIV aposentadoria; XXV - assistência gratuita aos filhos e dependentes desde o nascimento até 5 (cinco) anos de idade em creches e pré-escolas; XXVI - reconhecimento das convenções e acordos coletivos de trabalho; XXVII - proteção em face da automação, na forma da lei; XXVIII - seguro contra acidentes de trabalho, a cargo do empregador, sem excluir a indenização a que este está obrigado, quando incorrer em dolo ou culpa; XXIX - ação, quanto aos créditos resultantes das relações de trabalho, com prazo prescricional de cinco anos para os trabalhadores urbanos e rurais, até o limite de dois anos após a extinção do contrato de trabalho; XXX - proibição de diferença de salários, de exercício de funções e de critério de admissão por motivo de sexo, idade, cor ou estado civil; XXXI - proibição de qualquer discriminação no tocante a salário e critérios de admissão do trabalhador portador de deficiência; XXXII - proibição de distinção entre trabalho manual, técnico e intelectual ou entre os profissionais respectivos; XXXIII - proibição de trabalho noturno, perigoso ou insalubre a menores de dezoito e de qualquer trabalho a menores de dezesseis anos, salvo na condição de aprendiz, a partir de quatorze anos; XXXIV - igualdade de direitos entre o trabalhador com vínculo empregatício permanente e o trabalhador avulso. Parágrafo único. São assegurados à categoria dos trabalhadores domésticos os direitos previstos nos incisos IV, VI, VII, VIII, X, XIII, XV, XVI, XVII, XVIII, XIX, XXI, XXII, XXIV, XXVI, XXX, XXXI e XXXIII e, atendidas as condições estabelecidas em lei e observada a simplificação do cumprimento das obrigações tributárias, principais e acessórias, decorrentes da relação de trabalho e suas peculiaridades, os previstos nos incisos I, II, III, IX, XII, XXV e XXVIII, bem como a sua integração à previdência social. In: BRASIL. Constituição da República Federativa do Brasil de 1988. In: Diário Oficial da União, Brasília, DF, 050 out. $1988 . \quad$ Disponível em: <http://www.planalto.gov.br/ccivil_03/constituicao/constituicao.htm>. Acesso em: 18 Ago. 2018.

4 MARTINS, Sérgio Pinto. Direito do trabalho. 28a edição, Editora Atlas, São Paulo, 2012, p. 42. 
KOPSTEIN, Marcos Antunes; SILVA, Bruna Lopes. A flexibilização do direito trabalhista brasileiro. Revista Eletrônica Direito e Política, Programa de Pós-Graduação Stricto Sensu em Ciência Jurídica da UNIVALI, Itajaí, v.14, n.2, $2^{\circ}$ quadrimestre de 2019. Disponível em: www.univali.br/direitoepolitica - ISSN 1980-7791

Com efeito, os dispositivos subsequentes amparam o artigo supracitado. Dessa maneira, o disposto no art. $8^{\circ}$, da CF/88, versa sobre o sindicato e as suas relações, o art. 90 acerca das regras específicas para a greve, o art. 10 determina a participação dos trabalhadores em colegiados, e o art. 11 assegura, às empresas com mais de 200 empregados, a eleição de um representante dos trabalhadores para entendimentos com o empregador ${ }^{5}$.

Assim, vê-se que na própria $\mathrm{CF} / 88$, as garantias trabalhistas encontram um enorme respaldo protecionista ao trabalhador, tendo em vista que tem como base o princípio da dignidade da pessoa humana, o qual rege todo o regramento jurídico nacional e que, por consequência, exerce enorme influência nos princípios e normas trabalhistas.

Outrossim, quanto a estrutura e funções trabalhistas, nas suas particularidades, o direito do trabalho cumpre, dentre as normas e princípios intrínsecos, objetivos fortemente sociais, que valorizam o trabalho e a dignidade humana, embora tenha reflexos igualmente importantes na seara econômica, cultural e política. Relativo à importância do direito trabalhista, afirma Maurício Godinho Delgado ${ }^{6}$ que

Trata-se de segmento jurídico destacadamente teleológico finalístico, atado à meta de aperfeiçoar as condições de pactuação da força de trabalho na sociedade capitalista. Em consonância com isso, destaca-se por forte direcionamento interventivo na sociedade na economia e, principalmente, na vontade das partes contratuais envolvidas nas relações jurídicas que regula.

No que diz respeito à sua estrutura jurídica, é composto essencialmente por normas imperativas (e não dispositivas). Além disso, no seu cerne normativo tem decisiva presença os princípios jurídicos, notadamente seus princípios jurídicos especiais e os princípios jurídicos gerais, inclusive de matriz constitucional, que sejam valorizadores da dignidade da pessoa humana e do trabalho e emprego.

\footnotetext{
${ }^{5}$ MARTINS, Sérgio Pinto. Direito do trabalho. 28a edição, Editora Atlas, São Paulo, 2012.

${ }^{6}$ DELGADO, Maurício Godinho. Curso de Direito do Trabalho. 14a edição, São Paulo: Editora LTR, 2015, p. 67.
} 
KOPSTEIN, Marcos Antunes; SILVA, Bruna Lopes. A flexibilização do direito trabalhista brasileiro. Revista Eletrônica Direito e Política, Programa de Pós-Graduação Stricto Sensu em Ciência Jurídica da UNIVALI, Itajaí, v.14, n.2, $2^{\circ}$ quadrimestre de 2019. Disponível em: www.univali.br/direitoepolitica - ISSN 1980-7791

Desse entendimento, verifica-se que o cerne do Direito Trabalhista é a sua busca pela equalização entre a força laboral e o competitivo mercado capitalista formado por empresas que visam, acima de tudo, o lucro.

Neste ínterim, claramente as normas e princípios laborais que buscam a proteção da parte empregada, têm o condão de garantir o equilíbrio de forças da relação laboral. Isso porque, a orientação da legislação do trabalho no Brasil e na América Latina, em favor do empregado, nasceu de um contexto em que o Estado aliavase ao proletariado, que surgia com o deslocamento de poder das oligarquias rurais para as classes médias urbanas ${ }^{7}$.

Neste cenário, foi imputada ao Estado a proteção laboral e econômica para com o empregado, em uma tentativa de fomentar a indústria, e não às organizações sindicais, graças, mormente, à doutrina social cristã, socialista e as Convenções Internacionais da Organização Internacional do Trabalho (OIT). Para Alice Monteiro de $\operatorname{Barros}^{8}$, a transformação histórica que culminou nas garantias constitucionais é fruto de uma concepção política da época, que refletiu no ordenamento jurídico, evidentemente, também no direito do trabalho.

Outrossim, nota-se que, no decorrer da formação do direito laboral, esse moldouse de forma a proteger os direitos dos trabalhadores com grande influência estatal, enfraquecendo a negociação coletiva e a livre negociação.

Portanto, afere-se que as principais formas protecionistas são predispostas pelos princípios basilares laborais, quais sejam: princípio da proteção e suas subespécies, princípio da irrenunciabilidade de direitos, da continuidade da relação de emprego, da primazia da realidade, da inalterabilidade contratual lesiva e da irredutibilidade salarial.

Importante dessa forma, um breve escólio a respeito desses princípios que, posteriormente, elucidarão algumas questões concernentes à mudança de panorama no qual passa o direito trabalhista no Brasil.

\footnotetext{
7 RODRIGUeZ, Américo Plá. Princípios de Direito do Trabalho. Tradução: Wagner D. Gligio. $3^{a}$ edição, São Paulo: LTr, 2000.

${ }^{8}$ BARROS, Alice Monteiro de. Curso de direito do trabalho. 10a ed., São Paulo, LTR, 2016.
} 
KOPSTEIN, Marcos Antunes; SILVA, Bruna Lopes. A flexibilização do direito trabalhista brasileiro. Revista Eletrônica Direito e Política, Programa de Pós-Graduação Stricto Sensu em Ciência Jurídica da UNIVALI, Itajaí, v.14, n.2, $2^{\circ}$ quadrimestre de 2019. Disponível em: www.univali.br/direitoepolitica - ISSN 1980-7791

\subsection{Princípios basilares}

Antes de realizar propriamente uma análise mais minuciosa dos princípios supramencionados previamente, convém expor que todos os princípios e regramentos que embasam a Constituição Cidadã de 1988 baseiam-se e obedecem ao princípio geral da dignidade da pessoa humana, estabelecido no art. $1^{0}$ da supracitada que dispõe que

a República Federativa do Brasil, formada pela união indissolúvel dos Estados e Municípios e do Distrito Federal, constitui-se em Estado Democrático de Direito e tem como fundamentos: [...] III - a dignidade da pessoa humana. ${ }^{9}$

Ademais, também se podem enumerar outros princípios gerais que influem e têm enorme relevância para o Direito do Trabalho, quais sejam: os valores sociais do trabalho e da livre iniciativa, a inviolabilidade do direito à vida, à liberdade, à segurança e à propriedade, a igualdade entre os sexos e mais alguns que encontram disposição no art. $5^{0}$ da Lei Maior ${ }^{10}$.

Aponta-se também, a liberdade sindical, o direito de greve, o reconhecimento das convenções e acordos coletivos e a proteção contra a dispensa arbitrária, como os mais importantes regramentos acerca do Direito Trabalhista, predispostos pela Carta Magna e que são propriamente considerados como princípios constitucionais de Direito do Trabalho ${ }^{11}$.

Após explanação introdutória acerca dos princípios gerais e constitucionais que regem a seara trabalhista, destrincha-se de forma sucinta os principais preceitos trabalhistas que regulam e caracterizam o Direito do Trabalho, como um meio preservacionista da relação de emprego e de caráter protetivo em face da parte mais frágil, o empregado, que são: o princípio da proteção e suas subespécies, o princípio da irrenunciabilidade de direitos, o da continuidade da relação de

\footnotetext{
9 In: BRASIL. Constituição da República Federativa do Brasil de 1988. In: Diário Oficial da União, Brasília, 05 out. $1988 . \quad$ Disponível em: <http://www.planalto.gov.br/ccivil_03/constituicao/constituicao.htm>. Acesso em: 18 Ago. 2018

10 BARROS, Alice Monteiro de. Curso de direito do trabalho. 10a ed., São Paulo, LTR, 2016.

11 BARROS, Alice Monteiro de. Curso de direito do trabalho. 10a ed., São Paulo, LTR, 2016.
} 
KOPSTEIN, Marcos Antunes; SILVA, Bruna Lopes. A flexibilização do direito trabalhista brasileiro. Revista Eletrônica Direito e Política, Programa de Pós-Graduação Stricto Sensu em Ciência Jurídica da UNIVALI, Itajaí, v.14, n.2, $2^{\circ}$ quadrimestre de 2019. Disponível em: www.univali.br/direitoepolitica - ISSN 1980-7791

emprego, da primazia da realidade, da inalterabilidade contratual lesiva e da irredutibilidade salarial.

Foca-se, primordialmente, no princípio da proteção, uma vez que esse, além de embasar, influencia todos os outros princípios que serão aqui comentados. Tal princípio tem por intuito dirimir as diferenças entre empregador e empregados, visto que o primeiro possui força financeira, verificando-se assim um evidente desequilíbrio nas relações empregatícias. Coaduna com o exposto a afirmação de Godinho Delgado ${ }^{12}$ sobre o princípio da proteção:

Informa este princípio que o Direito do Trabalho estrutura em seu interior, com suas regras, institutos, princípios e presunções próprias, uma teia de proteção à parte hipossuficiente na relação empregatícia - o obreiro-, visando retificar (ou atenuar), no plano jurídico, o desequilíbrio inerente ao plano fático do contrato de trabalho.

Portanto, pode-se afirmar que, no Direito do Trabalho, o princípio da proteção tem importância vital, configurando-se, assim, no mais basilar e fundamental princípio trabalhista, pois "parte importante da doutrina aponta este princípio como o cardeal do Direito do Trabalho, por influir em toda a estrutura e características próprias desse ramo jurídico especializado."13

Sobre tais aspectos, Américo Plá Rodriguez ${ }^{14}$, um dos mais famosos doutrinadores internacionais acerca de direitos e princípios trabalhistas, predispõe os desígnios que revestem a proteção ao trabalhador que infere na norma jurídica ao relatar que "[...] a norma está inspirada pela finalidade de proteção ao trabalhador e, em consonância com essa finalidade, a aplicação deve efetuar-se com intuito de proteção, ou melhor, resolve os casos de dúvida em favor de quem deveria ser protegido".

\footnotetext{
12 DELGADO, Maurício Godinho. Curso de Direito do Trabalho. $11^{\text {a }}$ edição, São Paulo: Editora LTR, 2012, p. 193.

${ }^{13}$ DELGADO, Maurício Godinho. Curso de Direito do Trabalho. $11^{a}$ edição, São Paulo: Editora LTR, 2012, 193.

14 RODRIGUEZ, Américo Plá. Princípios de Direito do Trabalho. Tradução: Wagner D. Gligio. $3 a$ edição, São Paulo: LTr, 2000, p. 50.
} 
KOPSTEIN, Marcos Antunes; SILVA, Bruna Lopes. A flexibilização do direito trabalhista brasileiro. Revista Eletrônica Direito e Política, Programa de Pós-Graduação Stricto Sensu em Ciência Jurídica da UNIVALI, Itajaí, v.14, n.2, $2^{\circ}$ quadrimestre de 2019. Disponível em: www.univali.br/direitoepolitica - ISSN 1980-7791

Dessa maneira, afirma-se que do referido basilar princípio decorrem três outros princípios ou vertentes: princípio in dubio pro operario, da norma mais favorável e por fim da condição mais benéfica.

O princípio in dubio pro operario ou pro misero reconhece que o empregado é a parte hipossuficiente da relação contratual de trabalho, logo as normas trabalhistas a serem balizadas devem ser sempre aquelas mais benéficas ao trabalhador. Seguindo o raciocínio, o princípio da norma mais favorável adquire semelhanças para com o princípio anterior, mas, em contraste, possui uma peculiaridade importantíssima, qual seja, a ausência da hierarquia da norma trabalhista, utilizando-se o regramento mais benéfico ao trabalhador, pouco importando seu nível hierárquico ${ }^{15}$.

Por fim, o princípio da condição mais benéfica prevê que se preservarão, no decorrer do contrato de trabalho, as cláusulas mais vantajosas ao trabalhador, tratando-se assim de direito adquirido, sendo que essas vantagens jamais poderão ser anuladas.

Quanto ao princípio da irrenunciabilidade de direitos, Sérgio Pinto Martins dispõe:

Temos como regra que os direitos trabalhistas são irrenunciáveis pelo trabalhador: Não se admite, por exemplo, que o trabalhador renuncie a suas férias. Se tal fato ocorrer, não terá qualquer validade o ato do operário, podendo o obreiro reclamá-las na Justiça do Trabalho' ${ }^{16}$.

Desse entendimento, visualiza-se que o princípio da irrenunciabilidade estabelece a impossibilidade jurídica de privar o empregado das vantagens outrora concedidas em seara trabalhista. Portanto, tanto o empregador, quanto o empregado não podem dispensar direitos de ordem pública, ainda mais aqueles que visam, sobretudo, a proteção do trabalhador.

Suscintamente, no que se refere ao princípio da continuidade da relação de emprego, este predispõe que o vínculo empregatício deve ser mantido sempre que

\footnotetext{
15 TAKABAYASHI, Marcelo Midori. Direito do Trabalho e Processo do Trabalho. In: FIGUEIREDO, Fábio Vieira. Teoria Unificada. 4a edição, São Paulo: Editora Saraiva, 2013, p. 319-372.

16 MARTINS, Sérgio Pinto. Direito do trabalho. 28a edição, Editora Atlas, São Paulo, 2012, p. 70.
} 
KOPSTEIN, Marcos Antunes; SILVA, Bruna Lopes. A flexibilização do direito trabalhista brasileiro. Revista Eletrônica Direito e Política, Programa de Pós-Graduação Stricto Sensu em Ciência Jurídica da UNIVALI, Itajaí, v.14, n.2, $2^{\circ}$ quadrimestre de 2019. Disponível em: www.univali.br/direitoepolitica - ISSN 1980-7791

possível, devendo nortear-se, então, sempre no sentido de assegurar a permanência do trabalhador em seu emprego ${ }^{17}$.

Já o princípio da primazia da realidade estabelece que, no caso de desacordo entre a realidade fática e o que transmite os documentos acostados no processo trabalhista, deve-se privilegiar a verdade real, ou seja, no Direito do Trabalho "os fatos são mais importantes que os documentos."18

Quanto ao princípio da inalterabilidade contratual lesiva, este encontra sua caracterização através das disposições do art. 468 da CLT, que estabelece que "nos contratos individuais de trabalho só é lícita alteração das respectivas condições por mútuo consentimento, e ainda assim desde que não resultem, direta ou indiretamente, prejuízos ao empregado $[\ldots]^{\prime \prime 19}$.

Ainda, cita-se a irredutibilidade salarial, a qual encontra respaldo na Carta Magna de 1988 que estabelece em seu art. 70, inciso VI, a coibição da redução do salário do trabalhador pelo empregador, salvo ocorrência de negociação coletiva ${ }^{20}$.

Após feitura da análise dos princípios que regem a seara trabalhista, importante indagar a respeito da influência de tais regramentos nas grandes mudanças, ensejadas por um mercado de trabalho extremamente concorrido e por pressões cada vez mais fortes do ramo empresarial por desregulamentação de normas e flexibilização trabalhista, através de acordos ou convenções coletivas, as quais geram transformações no Direito Trabalhista.

\subsection{Da transformação das normas e da desregulamentação laboral}

\footnotetext{
17 TAKABAYASHI, Marcelo Midori. Direito do Trabalho e Processo do Trabalho. In: FIGUEIREDO, Fábio Vieira. Teoria Unificada. $4^{a}$ edição, São Paulo: Editora Saraiva, 2013, p. 319-372.

18 MARTINS, Sérgio Pinto. Direito do trabalho. 28a edição, Editora Atlas, São Paulo, 2012, p. 72.

19 BRASIL. Decreto-Lei no 5.452, de 01 de maio de 1943. Aprova a Consolidação das Leis do Trabalho. Disponível em:< http://www.planalto.gov.br/ccivil_03/decreto-lei/del5452.htm>. Acesso em: 18 ago. 2018.

20 BRASIL. Constituição da República Federativa do Brasil de 1988. Disponível em:<http://www.planalto.gov.br/ccivil_03/constituicao/constituicaocompilado.htm>. Acesso em: 16 ago. 2018.
} 
KOPSTEIN, Marcos Antunes; SILVA, Bruna Lopes. A flexibilização do direito trabalhista brasileiro. Revista Eletrônica Direito e Política, Programa de Pós-Graduação Stricto Sensu em Ciência Jurídica da UNIVALI, Itajaí, v.14, n.2, 20 quadrimestre de 2019. Disponível em: www.univali.br/direitoepolitica - ISSN 1980-7791

Depreende-se que, notadamente, ocorreu uma transfiguração do Direito Laboral e, segundo as palavras de Dorneles"21, tal direito passa por "um processo de descaracterização, uma vez que afronta [...] justamente sua lógica central".

Ocorre, assim, uma descaracterização da lógica preservacionista jurídico-social do trabalho, cerne central do processo trabalhista, tendo em vista que, por intermédio de desregulamentações e da flexibilização, averiguaram-se afrontas aos princípios fundamentais trabalhistas ${ }^{22}$.

A transformação do caráter preservacionista do processo trabalhista para uma lógica mais flexível se deu, principalmente, por mudanças no panorama econômico da sociedade brasileira. Consoante compreende Amauri Mascaro Nascimento ${ }^{23}$, tal situação se ensejou por algumas razões, a citar: "[...] um mercado de trabalho muito heterogêneo e em transformação. [...] e uma transferência de tutela de direitos econômicos para a negociação coletiva" e ainda porque "[...] para alguns a proteção da lei é desnecessária; para outros, o direito coletivo é suficiente e, para muitos, o direito individual, previsto em lei, é indispensável".

Destarte, a negociação coletiva representa umas das exemplificações mais latentes de flexibilização, sendo assim, a principal caracterização da relação laboral decorrente da nova transformação do Direito do Trabalho. Ainda, evidencia-se que, em um mercado de trabalho marcado por mudanças econômicas decorrentes de crises e evolução tecnológica, torna-se clara a conjuntura de uma reestruturação da relação de emprego, tornando-a mais maleável e suscetível a transações.

Quanto à evolução tecnológica, importante destacar, que essa tem repercutido de forma latente no âmbito do direito do trabalho, uma vez que tem a tendência de continuar aumentando o número de desempregados do país. A mencionada

\footnotetext{
${ }^{21}$ DORNELES, Leandro do Amaral D. de. A transformação do direito do trabalho: da lógica da preservação à lógica da flexibilidade. São Paulo: LTR, 2002, p. 11.

22 DORNELES, Leandro do Amaral D. de. A transformação do direito do trabalho: da lógica da preservação à lógica da flexibilidade. São Paulo: LTR, 2002.

23 NASCIMENTO, Amauri Mascaro. Painel: a flexibilização e as diferentes realidades socioeconômicos. In: Flexibilização no Direito do Trabalho. $2^{a}$ Edição, São Paulo: IOB Thomson, 2004 , p. 50.
} 
KOPSTEIN, Marcos Antunes; SILVA, Bruna Lopes. A flexibilização do direito trabalhista brasileiro. Revista Eletrônica Direito e Política, Programa de Pós-Graduação Stricto Sensu em Ciência Jurídica da UNIVALI, Itajaí, v.14, n.2, $2^{\circ}$ quadrimestre de 2019. Disponível em: www.univali.br/direitoepolitica - ISSN 1980-7791

tendência, todavia, é uma marca já em diversos países que adotam o processo de flexibilização do trabalho, o que gera profundas discussões na área trabalhista24.

Neste contexto, relevante destacar que dessas reflexões pode-se antever que a flexibilização do Direito do Trabalho já ocorre há certo tempo no ordenamento jurídico brasileiro. Citando-se como exemplos claros dessa transformação, tem-se o fim da estabilidade decenal (substituída totalmente pelo Fundo de Garantia do Tempo de Serviço) com o advento da CF/88, a desistência da incorporação no ordenamento jurídico da Convenção número 158 da OIT, a qual proíbe a demissão de empregado, excetuando a dispensa por justa causa, e ainda as ampliações das hipóteses legais de constituição de contratos de trabalho com prazo determinado ${ }^{25}$. Ainda, quanto à terceirização, o exemplo mais latente da flexibilização do trabalho, mostra-se o que essa, embora tenha sido ampliada em 2017 para atividades fim das empresas, há tempos que "[...] já faz parte da realidade brasileira. Sua prática, de forma equivocada, vem associada com o entendimento de que ela representa redução de custos para a empresa tomadora de seus serviços."26

Após explorar alguns aspectos referentes à transformação dos regramentos laborais, convém desenvolver mais a ideia do que é a flexibilização do trabalho e suas características mais marcantes.

\section{A FLEXIBILIZAÇÃO DO DIREITO DO TRABALHO}

\subsection{Conceito e tipos}

Torna-se oportuno conceituar, segundo o entendimento doutrinário, o que é a flexibilização do trabalho, suas definições e objetivos primordiais. Intui-se assim, maior compreensão no tocante ao que se trata a transformação que o Direito

${ }^{24}$ FERRAZ, Fernando Basto. Terceirização e demais formas de flexibilização do trabalho. São Paulo: LTR, 2006.

25 DORNELES, Leandro do Amaral D. de. A transformação do direito do trabalho: da lógica da preservação à lógica da flexibilidade. São Paulo: LTR, 2002.

${ }^{26}$ FERRAZ, Fernando Basto. Terceirização e demais formas de flexibilização do trabalho. São Paulo: LTR, 2006, p. 12. 
KOPSTEIN, Marcos Antunes; SILVA, Bruna Lopes. A flexibilização do direito trabalhista brasileiro. Revista Eletrônica Direito e Política, Programa de Pós-Graduação Stricto Sensu em Ciência Jurídica da UNIVALI, Itajaí, v.14, n.2, $2^{\circ}$ quadrimestre de 2019. Disponível em: www.univali.br/direitoepolitica - ISSN 1980-7791

Laboral brasileiro tem passado. Primeiramente, indispensável expressar o entendimento de Delgado ${ }^{27}$ sobre a flexibilização:

Por flexibilização trabalhista entende-se a possibilidade jurídica, estipulada por norma estatal ou por norma coletiva negociada, de atenuação da força imperativa das normas componentes do Direito do Trabalho, de modo a mitigar a amplitude de seus comandos o/ou os parâmetros próprios para a sua incidência. Ou seja, trata-se da diminuição da imperatividade das normas justrabalhistas ou da amplitude de seus efeitos, em conformidade com autorização fixada por norma heterônoma estatal ou por norma coletiva negociada.

Nessa mesma percepção, Ferraz ${ }^{28}$ fundamenta que "consideramos a flexibilização do trabalho a adequação das normas trabalhistas às exigências econômicas do mundo globalizado, que culmina com a precarização da relação formal de emprego".

Pode-se interpretar, assim, que a flexibilização decorre de uma quebra da influência estatal na economia, gerando uma abertura maior para a livre negociação. O caráter protecionista das normas laborais, não mais coaduna com as políticas econômicas neoliberais marcadas pelo avanço tecnológico e por um mercado de trabalho mais competitivo, que exige mão-de-obra mais qualificada e maleável quanto às tratativas concernentes ao contrato de trabalho.

Com efeito, para Dorneles 29 , o fenômeno corresponde a uma "(des)ordem" social, a qual apoia a eliminação de maior parte das normas trabalhistas, uma vez que entende que essas obstam a competitividade e o crescimento da economia de mercado. Para além, a flexibilização é constituída como uma das principais medidas de estabilidade econômica-social, na visão capitalista formada nos moldes das propostas neoliberais.

${ }^{27}$ DELGADO, Maurício Godinho. Curso de Direito do Trabalho. 14a edição, São Paulo: Editora LTR, 2015, p. 57.

${ }^{28}$ FERRAZ, Fernando Basto. Terceirização e demais formas de flexibilização do trabalho. São Paulo: LTR, 2006, p. 18.

29 DORNELES, Leandro do Amaral D. de. A transformação do direito do trabalho: da lógica da preservação à lógica da flexibilidade. São Paulo: LTR, 2002, p. 139. 
KOPSTEIN, Marcos Antunes; SILVA, Bruna Lopes. A flexibilização do direito trabalhista brasileiro. Revista Eletrônica Direito e Política, Programa de Pós-Graduação Stricto Sensu em Ciência Jurídica da UNIVALI, Itajaí, v.14, n.2, $2^{\circ}$ quadrimestre de 2019. Disponível em: www.univali.br/direitoepolitica - ISSN 1980-7791

Coaduna-se com o supramencionado, o entendimento de Martins ${ }^{30}$ sobre a flexibilização do trabalho, o qual explana que:

O Direito do Trabalho é um ramo da ciência do Direito muito dinâmico, que vem sendo modificado constantemente, principalmente para resolver o problema do capital e do trabalho. Para adaptar esse dinamismo à realidade laboral, surgiu uma teoria chamada de flexibilização dos direitos trabalhistas.

A flexibilização das condições de trabalho é um conjunto de regras que têm por objetivo instituir mecanismos tendentes a compatibilizar as mudanças de ordem econômica, tecnológica ou social existentes na relação entre o capital e o trabalho.

Destaca-se, que a flexibilização do trabalho, pode ser classificada quanto a sua finalidade, objeto e forma. Quanto à finalidade, a flexibilização pode ser interpretada com o fim protecionista, tomando-se em conta a modificação de direitos em benefício ao trabalhador; de adaptação das normas legais rígidas à negociação coletiva, deixando-se às partes, empregado e empregador, a valoração do que é mais conveniente na situação posta; e, de desregulamentação ${ }^{31}$.

Quanto ao objeto, relevante destacar que a flexibilização do trabalho pode ter caráter interno ou externo. No que se tange à flexibilização interna, ela abarca situações relativas à relação de trabalho preexistente, modificando, assim, o próprio contrato de trabalho do empregado, como no caso das alterações na jornada de trabalho, nos horários, nas condições de labor e remuneração. Exemplifica-se a flexibilização interna, mencionando o regime de trabalho em tempo parcial e a suspensão do contrato de trabalho para que o empregado participe de cursos de qualificação ${ }^{32}$.

Já a flexibilização externa, versa sobre influências extrínsecas ao contrato de trabalho, ou seja, alude-se a aspectos quanto ao incentivo ao ingresso e restrição a saída do mercado de trabalho, indicando questões quanto ao salário, tipos de contratação, restrições à dispensa. Ainda, no que se refere à forma, a flexibilização

\footnotetext{
30 MARTINS, Sérgio Pinto. Direito do trabalho. 28a edição, Editora Atlas, São Paulo, 2012, p. 539.

31 DORNELES, Leandro do Amaral D. de. A transformação do direito do trabalho: da lógica da preservação à lógica da flexibilidade. São Paulo: LTR, 2002.

32 BARROS, Alice Monteiro de. Curso de direito do trabalho. 10a ed., São Paulo, LTR, 2016.
} 
KOPSTEIN, Marcos Antunes; SILVA, Bruna Lopes. A flexibilização do direito trabalhista brasileiro. Revista Eletrônica Direito e Política, Programa de Pós-Graduação Stricto Sensu em Ciência Jurídica da UNIVALI, Itajaí, v.14, n.2, $2^{\circ}$ quadrimestre de 2019. Disponível em: www.univali.br/direitoepolitica - ISSN 1980-7791

pode ser autônoma ou heterônoma. A flexibilização autônoma decorre de acordo ou convenção coletiva, ou seja, não sofre influência estatal, já a flexibilização heterônoma é imposta pelo Estado através da desregulamentação das normas trabalhistas ${ }^{33}$.

Após explanação a respeito dos tipos de flexibilização, importante dispor das argumentações de Barros $^{34}$ que disserta que:

O fenômeno da flexibilização é encarado também sob o enfoque da "desregulamentação normativa", imposta pelo Estado, a qual consiste em derrogar vantagens de cunho trabalhista, substituindo-as por benefícios inferiores. A "desregulamentação normativa" imposta unilateralmente pelo Estado (flexibilização heterônoma) é considerada por alguns doutrinadores como "selvagem". Em contrapartida a ela, sugere-se uma "regulamentação laboral de novo tipo", a qual pressupõe a substituição das garantias legais pelas garantias convencionais (flexibilização autônoma), com a primazia da negociação coletiva.

Conclui-se, após análise do conceito da flexibilização do trabalho, que ela advém especialmente quando da ocorrência de modificações do panorama sociopolítico de um país. Adentrando no exemplo do Brasil, quando da substituição da estabilidade decenal pelo Fundo de Garantia, o país passava por uma severa crise econômica, marcada pela alta inflação e desemprego.

Hodiernamente, uma nova crise avassala o país, acarretando em intensos debates sobre reformas não somente na esfera trabalhista, mas também na Previdência Social. Sendo assim, torna-se demasiadamente importante discutir esses aspectos referentes à mudança de panorama econômico e sua influência na transformação do Direito do Trabalho.

\subsection{Da mudança de panorama econômico}

\footnotetext{
33 DORNELES, Leandro do Amaral D. de. A transformação do direito do trabalho: da lógica da preservação à lógica da flexibilidade. São Paulo: LTR, 2002.

${ }^{34}$ BARROS, Alice Monteiro de. Curso de direito do trabalho. 10a ed., São Paulo, LTR, 2016, p. 65.
} 
KOPSTEIN, Marcos Antunes; SILVA, Bruna Lopes. A flexibilização do direito trabalhista brasileiro. Revista Eletrônica Direito e Política, Programa de Pós-Graduação Stricto Sensu em Ciência Jurídica da UNIVALI, Itajaí, v.14, n.2, $2^{\circ}$ quadrimestre de 2019. Disponível em: www.univali.br/direitoepolitica - ISSN 1980-7791

Seguindo a exposição, constata-se que ocorreram, e ainda ocorrem, mudanças no panorama econômico no país e no mundo. Tal situação é ensejada pela globalização e por novas tecnologias que acarretaram aumento de desemprego e a precarização do trabalho. Acresce-se a isso, o aumento considerável de crises financeiras que abalaram fortemente os setores secundários e terciários da economia, os quais abarcam a maioria da mão-de-obra do mercado laboral. Sobre tal situação e sua influência nas relações de trabalho, expõe-se que:

São grandes as transformações no mundo das relações de trabalho. A conjuntura internacional mostra uma sociedade exposta a sérios problemas que atingiram em escala mundial os sistemas econômicos capitalistas. Os empregos diminuíram, cresceram outras formas de trabalho sem vínculo de emprego, as empresas passaram a produzir mais com pouca mão de obra, a informática e a robótica trouxeram produtividade crescente e trabalho decrescente. ${ }^{35}$

No atual cenário econômico, ocorre, no Brasil, uma ampliação da desigualdade social e do desemprego, os quais têm forte ingerência nas relações de trabalho, gerando, inclusive, um crescimento do mercado de trabalho informal, que não garante todo o caráter protecionista pregoado pelas normas e princípios trabalhistas. Para mais, há de se mencionar os efeitos de um mundo globalizado e marcado por inovações tecnológicas que substituem o labor humano ${ }^{36}$.

Desse porte, os setores do Direito do Trabalho afetados pelos reflexos da globalização são muitos, pois tal conjectura gera redução de empregos e descentralização de atividades de empresas através de subcontratações (adentrando-se particularmente na questão da terceirização). Assim, muitos trabalhadores não possuem alternativa, senão aceitar tal situação que enseja a brutal falta de garantias trabalhistas. Pode-se ainda enumerar como reflexo da globalização, a requalificação profissional do empregado, tendo em vista que, no competitivo mercado de trabalho, exige-se maior aptidão da mão-de-obra ${ }^{37}$.

\footnotetext{
35 NASCIMENTO, Amauri Mascaro. Curso de Direito do Trabalho. 26a Edição. Editora Saraiva, 2011, p. 69.

${ }^{36}$ BARROS, Alice Monteiro de. Curso de direito do trabalho. 10a ed., São Paulo, LTR, 2016.

37 NASCIMENTO, Amauri Mascaro. Curso de Direito do Trabalho. 26a Edição. Editora Saraiva, 2011.
} 
KOPSTEIN, Marcos Antunes; SILVA, Bruna Lopes. A flexibilização do direito trabalhista brasileiro. Revista Eletrônica Direito e Política, Programa de Pós-Graduação Stricto Sensu em Ciência Jurídica da UNIVALI, Itajaí, v.14, n.2, 20 quadrimestre de 2019. Disponível em: www.univali.br/direitoepolitica - ISSN 1980-7791

A globalização, além do mais, exerce influência gigantesca no processo de flexibilização do trabalho, pois segundo Dorneles ${ }^{38}$ :

O Estado estaria perdendo a pretensão na detenção do monopólio de promulgar regras. A internacionalização e a maior mobilidade empresarial e produtiva permitiriam às empresas "jogar" de forma fácil e eficiente com as diferentes legislações nacionais. Assim, cada Estado teria que levar em conta a situação internacional para promulgar leis nacionais, sob pena de perder a competitividade no cenário global. Dessa forma, verifica-se uma tendência de maior flexibilidade do Direito, tendendo a este a perder seu caráter de monopólio regulador centralizado e a se dispersar em vários níveis de formulação.

No caso do Brasil, é latente a enorme influência de multinacionais e grandes empresários no cenário político e econômico do país, sendo que as exigências desses por maior competitividade e incentivos à economia acabam insuflando debates acerca do Direito Trabalhista e seu caráter preservacionista ${ }^{39}$.

Destarte, antevê-se que a transformação do Direito do Trabalho decorre, acima de tudo, das oscilações econômicas de esfera, inclusive, global, sendo que tal situação gera flexibilizações do trabalho com ênfase nas negociações coletivas e desregulamentações estatais:

Assim, a diversificação dos temas centrais das relações de trabalho opera em um novo quadro socioeconômico no qual se combinam elementos de flexibilização e intervencionismo diante de um mercado de trabalho fragmentado e de uma força de trabalho reduzida, característica da época contemporânea. ${ }^{40}$

Indispensável nesse interim, estabelecer a transmutação da lógica da preservação para à lógica da flexibilidade decorrentes da transformação do Direito do Trabalho.

38 DORNELES, Leandro do Amaral D. de. A transformação do direito do trabalho: da lógica da preservação à lógica da flexibilidade. São Paulo: LTR, 2002, p. 115.

39 DORNELES, Leandro do Amaral D. de. A transformação do direito do trabalho: da lógica da preservação à lógica da flexibilidade. São Paulo: LTR, 2002.

40 NASCIMENTO, Amauri Mascaro. Curso de Direito do Trabalho. 26a Edição. Editora Saraiva, 2011, p. 76. 
KOPSTEIN, Marcos Antunes; SILVA, Bruna Lopes. A flexibilização do direito trabalhista brasileiro. Revista Eletrônica Direito e Política, Programa de Pós-Graduação Stricto Sensu em Ciência Jurídica da UNIVALI, Itajaí, v.14, n.2, 20 quadrimestre de 2019. Disponível em: www.univali.br/direitoepolitica - ISSN 1980-7791

\subsection{Da preservação à flexibilidade}

Designa-se, dessa maneira, uma readequação do Direito do Trabalho, acompanhando as transmutações pelas quais passa a sociedade e, por consequência, o mercado de trabalho. Outrora, no século passado, a influência do Estado na economia era particularmente relevante, para tanto o próprio Estado desenvolveu normas trabalhistas com intuito preservacionista. Na época atual, o neoliberalismo influi grandemente nos aspectos econômicos, políticos e sociais da nação. Relevante assim, analisar o apanhado histórico, notavelmente descrito por Alice Monteiro de Barros ${ }^{41}$ :

Como se vê, o Direito do Trabalho surgiu em momento histórico de crise, como resposta política aos problemas sociais acarretados pelos dogmas do capitalismo liberal. [...] Diante das agitações dos trabalhadores e das lutas sociais no continente europeu, o Estado resolveu intervir na regulamentação do trabalho, inspirando-se em normas que Ihe atribuem critérios próprios, não encontrados em outro ramo do Direito. Essas normas são os princípios peculiares do Direito do Trabalho, entre os quais está o da proteção, centralizado numa garantia de condições mínimas de trabalho, sustentadas por um outro princípio, o da irrenunciabilidade.

Por consequência da influência europeia, o ordenamento jurídico pátrio, notadamente a CLT, que se assentou fundamentalmente na Carta del Lavoro da Itália, sempre embasou-se no princípio da proteção ao trabalhador e no caráter preservacionista do Direito Laboral focado na "socialização do emprego e do salário [...]" que intui "organizar limites humanizadores para a inserção do trabalhador na lógica de exploração tipicamente capitalista." ${ }^{42}$

Reitera-se, destarte, que as relações individuais de trabalho estão experimentando uma extensa reorganização decorrente do desenvolvimento de um sistema econômico neoliberal e da parca influência estatal na economia atual, de diversas crises no mercado de trabalho promovidas por enfraquecimento da economia e

\footnotetext{
41 BARROS, Alice Monteiro de. Curso de direito do trabalho. 10a ed., São Paulo, LTR, 2016, p. 63 e 64.

42 DORNELES, Leandro do Amaral D. de. A transformação do direito do trabalho: da lógica da preservação à lógica da flexibilidade. São Paulo: LTR, 2002, p. 170.
} 
KOPSTEIN, Marcos Antunes; SILVA, Bruna Lopes. A flexibilização do direito trabalhista brasileiro. Revista Eletrônica Direito e Política, Programa de Pós-Graduação Stricto Sensu em Ciência Jurídica da UNIVALI, Itajaí, v.14, n.2, $2^{\circ}$ quadrimestre de 2019. Disponível em: www.univali.br/direitoepolitica - ISSN 1980-7791

alta inflação, de modificações na forma de organização da produção industrial e do aumento do desemprego e da informalização do labor, dentre outros fatores ${ }^{43}$.

Ademais, essa recaracterização do direito trabalhista não ocorre apenas no Brasil, como também em grande parte de países outrora garantistas como Espanha, Portugal e México ${ }^{44}$, a flexibilização normativa se encontra em voga, e consoante Américo Plá Rodriguez ${ }^{45}$ :

Reconhecida a existência da globalização, convém assinalar que a linha de argumentação a que muita gente costuma recorrer, é muito esquemática e por demais simplificada: a globalização gera competitividade e esta conduz à flexibilidade trabalhista.

Nesse aspecto, reitera-se que apenas a globalização e a alta competividade do mercado não são os únicos motivos para o fomento à flexibilização, pois as crises econômicas, as novas tecnologias e o induzimento às negociações coletivas também ensejam tais transfigurações do direito laboral.

Dessa maneira, tais mudanças drásticas geram em uma extensa transmutação do Direito do Trabalho, recaindo numa tentativa cada vez mais latente de flexibilização do trabalho e desregulamentação das normas trabalhistas. Sobre isso, Amauri Masco Nascimento ${ }^{46}$ explana que:

O direito do trabalho vive atualmente um conflito entre as suas concepções, a protecionista, acusada de hipergarantista, de afetar o desenvolvimento econômico e a livre iniciativa, e a reformista que defende a flexibilização das leis e a reavaliação, no plano teórico, dos seus princípios e funções, pondo-se a flexibilização como uma polêmica reação contrária à rigidez da legislação tutelar do trabalhador.

Disso, pode-se dizer que o Direito do Trabalho, apesar de tentar ainda conservar suas características primordiais de proteção e preservação ao trabalhador, intenta

\footnotetext{
${ }^{43}$ BARROS, Alice Monteiro de. Curso de direito do trabalho. 10a ed., São Paulo, LTR, 2016.

${ }^{44}$ BARROS, Alice Monteiro de. Curso de direito do trabalho. 10a ed., São Paulo, LTR, 2016, p. 524.

45 RODRIgUeZ, Américo Plá. Princípios de Direito do Trabalho. Tradução: Wagner D. Gligio. $3 a$ edição, São Paulo: LTr, 2000, p. 30.

46 NASCIMENTO, Amauri Mascaro. Curso de Direito do Trabalho. 26a Edição. Editora Saraiva, 2011, p. 68.
} 
KOPSTEIN, Marcos Antunes; SILVA, Bruna Lopes. A flexibilização do direito trabalhista brasileiro. Revista Eletrônica Direito e Política, Programa de Pós-Graduação Stricto Sensu em Ciência Jurídica da UNIVALI, Itajaí, v.14, n.2, $2^{\circ}$ quadrimestre de 2019. Disponível em: www.univali.br/direitoepolitica - ISSN 1980-7791

não obstruir o avanço econômico e tecnológico, flexibilizando-se, sobretudo através do incentivo à negociação coletiva.

Aliás, essa é a pauta primordial que enseja a ocorrência desse fenômeno de mutação do direito trabalhista não somente no Brasil, mas em caráter, inclusive, mundial, pois "[...] el mundo laboral vive un periodo de restauración productiva, cuyo objetivo parece centrarse en socavar la rigidez jurídico-laboral y en privilegiar la modernización laboral $[\ldots]^{\prime \prime 47}$.

Outrossim, vê-se que o Direito do Trabalho contemporâneo substitui alguns aspectos de sua natureza preservacionista para uma natureza marcada pela flexibilidade nas relações de trabalho, intuindo como "meta principal a defesa do emprego e não mais a ampliação de direitos trabalhistas."48

\section{CONSIDERAÇÕES FINAIS}

Hodiernamente, o processo de flexibilização do Direito do Trabalho desenvolve-se e amplia sua influência em todas as camadas das relações de trabalho, tornandoas mais maleáveis e suscetíveis à livre negociação entre empregador e empregados, com uma clara diminuição da interferência estatal.

A transformação do Direito do Trabalho do ponto de vista de uma lógica preservacionista para uma lógica de flexibilidade acompanha uma readequação de ideais que visam, acima de tudo, uma maior liberdade de contratação, através de negociação coletiva entre sindicados e empresas e de desregulamentação de normas laborais consideradas retrógradas ou deveras protecionistas.

\footnotetext{
${ }^{47}$ Em tradução livre: "o mundo do trabalho está passando por um período de restauração produtiva, cujo objetivo parece ser minar a rigidez jurídico-laboral e privilegiar a modernização do trabalho". CUEVA, Octavio Lóyzaga de la. La flexibilidad laboral en México, antecedentes y perspectivas. México, 2006, p. 3. Disponível em:< https://www.azc.uam.mx/publicaciones/alegatos/pdfs/26/29-06.pdf>. Acesso em: 22 set. 2018.

48 NASCIMENTO, Amauri Mascaro. Curso de Direito do Trabalho. 26a Edição. Editora Saraiva, 2011, p. 70.
} 
KOPSTEIN, Marcos Antunes; SILVA, Bruna Lopes. A flexibilização do direito trabalhista brasileiro. Revista Eletrônica Direito e Política, Programa de Pós-Graduação Stricto Sensu em Ciência Jurídica da UNIVALI, Itajaí, v.14, n.2, $2^{\circ}$ quadrimestre de 2019. Disponível em: www.univali.br/direitoepolitica - ISSN 1980-7791

Os princípios básicos trabalhistas perdem assim preponderância em face das novas tendências e exigências de um mercado de trabalho mais competitivo e de abalos econômicos que afetam todas as camadas da sociedade brasileira.

O cerne central e justificativa de políticos para fomentar a flexibilização trabalhista, é no sentido de que as relações entre empregadores e empregados necessitam de modernização, permitindo assim que estes possam negociar com maior liberalidade e com a mínima intervenção estatal possível.

A globalização e o modelo neoliberal, o qual influi profusamente na política econômica, afetam toda a seara trabalhista, da legislação às relações laborais propriamente. Sendo assim, tanto pela influência externa, quanto interna, a sociedade brasileira vai moldando-se e adaptando-se a novos modelos laborais, marcadamente o aumento de subcontratações através de terceirizações e da flexibilização de direito trabalhistas, outrora rigidamente protegidos pela legislação trabalhista pátria.

\section{REFERÊNCIA DAS FONTES CITADAS}

BARROS, Alice Monteiro de. Curso de direito do trabalho. $10^{a}$ ed., São Paulo, LTR, 2016.

BRASIL. Constituição da República Federativa do Brasil de 1988. Disponível em:<http://www.planalto.gov.br/ccivil_03/constituicao/constituicaocompilado.ht m>. Acesso em: 16 ago. 2018.

BRASIL. Decreto-Lei no 5.452, de 01 de maio de 1943. Aprova a Consolidação das Leis do Trabalho. Disponível em:< http://www.planalto.gov.br/ccivil_03/decreto-lei/del5452.htm>. Acesso em: 18 ago. 2018.

CUEVA, Octavio Lóyzaga de la. La flexibilidad laboral en México, antecedentes y perspectivas. México, 2006. Disponível em:<https://www.azc.uam.mx/publicaciones/alegatos/pdfs/26/29-06.pdf>. Acesso em: 22 set. 2018.

DELGADO, Maurício Godinho. Curso de Direito do Trabalho. $11^{\text {a }}$ edição, São Paulo: Editora LTR, 2012. 
KOPSTEIN, Marcos Antunes; SILVA, Bruna Lopes. A flexibilização do direito trabalhista brasileiro. Revista Eletrônica Direito e Política, Programa de Pós-Graduação Stricto Sensu em Ciência Jurídica da UNIVALI, Itajaí, v.14, n.2, $2^{\circ}$ quadrimestre de 2019. Disponível em: www.univali.br/direitoepolitica - ISSN 1980-7791

DELGADO, Maurício Godinho. Curso de Direito do Trabalho. 14a edição, São Paulo: Editora LTR, 2015.

DORNELES, Leandro do Amaral D. de. A transformação do direito do trabalho: da lógica da preservação à lógica da flexibilidade. São Paulo: LTR, 2002.

FERRAZ, Fernando Basto. Terceirização e demais formas de flexibilização do trabalho. São Paulo: LTR, 2006.

Flexibilização no Direito do Trabalho. 2a Edição, São Paulo: IOB Thomson, 2004.

MARTINS, Sérgio Pinto. Direito do trabalho. $28^{a}$ edição, Editora Atlas, São Paulo, 2012.

NASCIMENTO, Amauri Mascaro. Curso de Direito do Trabalho. $26^{a}$ Edição. Editora Saraiva, 2011.

NASCIMENTO, Amauri Mascaro. Painel: a flexibilização e as diferentes realidades socioeconômicos. In: Flexibilização no Direito do Trabalho. $2^{a}$ Edição, São Paulo: IOB Thomson, 2004.

RODRIGUEZ, Américo Plá. Princípios de Direito do Trabalho. Tradução: Wagner D. Gligio. $3^{a}$ edição, São Paulo: LTr, 2000.

TAKABAYASHI, Marcelo Midori. Direito do Trabalho e Processo do Trabalho. In: FIGUEIREDO, Fábio Vieira. Teoria Unificada. 4a edição, São Paulo: Editora Saraiva, 2013, p. 319-372.

RECEBIDO EM: 30/01/2019

APROVADO EM: 22/03/2019 